\title{
PENGGUNAAN TEKNOLOGI NFC-RFID DAN VANETS-DSRC DI SISTEM GERBANG TOL OTOMATIS UNTUK MENGURANGI KEMACETAN PADA PINTU TOL
}

\author{
Kukuh Aris Santoso ${ }^{1}$ \\ ${ }^{1}$ Universitas 17 Agustus 1945 Jakarta, Indonesia
}

\begin{tabular}{ll}
\hline Keyword & Abstrac \\
\hline NFC & The E-Tol concept is a solution that allows the reduction of congestion \\
RFID & at toll gates because so as to reduce the intensity of the accumulation \\
VANETS & of vehicles at toll gates, there are several solutions offered, namely an \\
DSRC & automated toll gate system based on Paste Cards using Near Fear \\
& Communication (NFC) Technology. ) based on Radio Frequency \\
& Identification (RFID) and Automated Technology based on Vehicle \\
Corresponding Author & Ad-Hoc Networks (VANETS) that utilizes Dedicated Short Range \\
\hline Kukuh Aris Santoso & Communication (DSRC) Near Fear Communication (NFC) \\
Universtias 17 Agustus & technology based on RFID based on a frequency of 13.56 MHz, with \\
1945 Jakarta & a distance of up to 10 cm. The data exchange speed reaches 42 \\
Indonesia & kilobits/s. Communication (NFC) Standardization of communication \\
Email: & protocol and NFC data exchange, which is based on radio frequency \\
kukuhpwu@gmail.com & identification (RFID) standards, including ISO/IEC 14443 and DSRC \\
& having an operating frequency of 5.9 GHz (5850-5925 MHz) with a \\
& bandwidth of 75Mhz, with standardization technology according to \\
& IEEE 802.11a that uses Orthogonal frequency-division multiplexing \\
& (OFDM) modulation.
\end{tabular}

\begin{abstract}
Abstrak
Konsep E-Tol menjadi sebuah solusi yang memungkinkan pengurangan kemacetan yang terdapat di pintu tol karena sehingga dapat mengurangi intensitas penumpukan kendaraan di pintu Tol, ada beberapa solusi yang ditawarkan yaitu dengan sistem pintu tol otomasi yang berdasarkan Menempelkan Kartu yang menggunakan Teknologi Near Fear Communication (NFC) berbasis Radio Frequency Identifikasi (RFID) dan Teknologi otomatis berbasis Vehicle Ad-Hoc Networks (VANETS) yang memanfaatkan teknologi Dedicated Short Range Comunication (DSRC) Near Fear Communication (NFC) yang berbasis pada berbasis RFID pada frekuensi $13.56 \mathrm{MHz}$, dengan jarak hingga $10 \mathrm{~cm}$. Kecepatan pertukaran data mencapai 42 kilobits/s. Communication (NFC) Standarisasi komunikasi protocol dan pertukaran data NFC, yaitu berdasarkan standar indentifikasi frekuensi radio (RFID), termasuk ISO/IEC 14443 dan DSRC mempunyai frekuensi operasi di 5,9 GHz (5850-5925 MHz) dengan bandwidth yaitu 75Mhz, dengan standarisasi teknologi menurut IEEE 802.11a yang menggunakan modulasi Orthogonal frequency-division multiplexing (OFDM).
\end{abstract}

Kata Kunci: NFC, RFID, VANETS, DSRC

\section{PENDAHULUAN}

Pendahuluan Kemacetan merupakan sebuah masalah yang mendapat perhatian serius, karena berdampak bagi kehidupan manusia, khususnya sangat terasa di ibukota Jakarta yang banyak aktifitas memerlukan waktu yang banyak, sering kali waktu yang di gunakan untuk mejalankan aktifitas terbuang percuma di jalan karena macet. Selain waktu yang terbuang sia sia di jalan, ada dampat negatif lainnya yaitu dampak kesehatan yang timbulkan, yaitu semakin banyaknya kendaraan yang terjebak dalam sebuah 
kemacetan, maka asap polusi yang mengandung zat zat racun bagi tubuh semakin banyak, sehingga udara bersih yang di hasilkan tanaman tercemar oleh asap polusi yang di timbulkan.

Berdasarkan hasil Penelitian tahun 2012, pada Gerbang tol Karawang barat yang berjudul ANALISIS KAPASITAS GERBANG TOL KARAWANG BARAT, didapatkan volume kendaraan pada gardu exit gerbang tol Karawang Barat sebesar 889 kendaraan/jam dan didapatkan rata-rata nilai waktu pelayanan sebesar 13.5 detik/kendaraan (Winarsih,N., \& Kusumaningrum, J. ,2013).

Dari segi ekonomi, BBM yang terbuang percuma karena kemacetan sangat besar, di Jabodetabek sendiri pada tahun 2019 hampir mencapai 655 trilliun rupiah kerugian yang di timbulkan, karena kemacetan di Jabodetabek (Liputan6.com,2019). Karenanya perlu dikembangan serta di implementasikan system otomatis pada titik kemacetan untuk mengurangi waktu yang di habiskan akibat kemacetan.

Konsep E-Tol menjadi sebuah solusi yang memungkinkan pengurangan kemacetan yang terdapat di pintu tol karena sehingga dapat mengurangi intensitas penumpukan kendaraan di pintu Tol, beberapa konsep ditawarkan yaitu dengan memanfaatkan system menempelkan kartu atau tapping kartu yang berbasis pada teknologi Near Fear Communication (NFC) berbasis Radio Frequency Identifikasi (RFID) dan Teknologi otomatis berbasis Vehicle Ad-Hoc Networks (VANETS) yang memanfaatkan teknologi Dedicated Short Range Comunication (DSRC). Teknologi terbaru Vanet -DSRC ini di uji coba pada pintu tol Kalimalang II Jakarta.

\section{METODE}

Metode yang digunakan dengan membandingkan kecepatan dalam service yang pernah diteliti dan dilakukan oleh kedua teknologi yaitu NFC-RFID dan VANETS DSRC.

\section{A. NFC - RFID}

Near Fear Communication (NFC) yang berbasis pada berbasis RFID pada frekuensi 13.56 MHz, dengan jarak hingga $10 \mathrm{~cm}$. Kecepatan pertukaran data mencapai 42 kilobits/s. Communication (NFC) Standarisasi komunikasi protocol dan pertukaran data NFC, yaitu berdasarkan standar indentifikasi frekuensi radio (RFID), termasuk ISO/IEC 14443. Standarisasinya termasuk ISO/IEC 18092, dan didefinisikan oleh Forum NFC, ditemukan pada tahun 2004 oleh Philips Semiconductors, (menjadi NXP Semiconductor sejak 2006), Nokia, Sony sekarang memiliki lebih dari 160 anggota. RFID harus menggunakan peralatan khusus, tidak bisa digunakan personal, sehingga pemanfaatannya kurang. Sedangkan NFC bisa digunakan secara personal, karena diintegrasikan pada Smartphone. NFC sendiri mirip dengan Bluetooth \& WiFi, yaitu melakukan koneksi Wireless berbasis frekuensi radio. Hal ini terlihat pada gambar 1.

\section{Mode Emulasi Kartu Near Field}

Communication (NFC) NFC biasanya terdiri dari dua bagian, yaitu Controler NFC dan elemen aman (Secure Elemen). Controler NFC berkomunikasi dengan Secure Elemen, bertanggung jawab untuk mengenkripsi, mendeskripsi data sensitif. Secure Elemen melakukan koneksi ke Controller NFC, melalui Bus Single Wire Protocol (SWP) dan Digital Contactless Bridge (DCLB).

2. Mode Peer To Peer Near Field Communication (NFC).

Dua perangkat NFC dapat berkomunikasi secara langsung, dan mudah berbagi data berukuran kecil. Dua perangkat NFC juga dapat berbagi data, konfigurasi dengan satu sama lain dan membangun koneksi Bluetooth atau WiFi, untuk berbagi data yang besar. Mode ini tidak diperlukan Secure Elemen. 
3. Mode Pembaca / Penulis Near Field

Communicaion (NFC) Mode ini, NFC dapat membaca atau menulis. Contoh, membaca informasi dari penguna lain, dapat juga mengakses tautan.

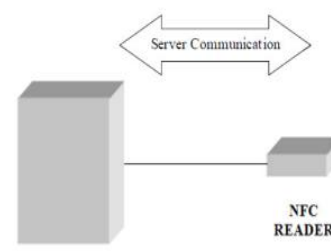

PAYMENT SERVER

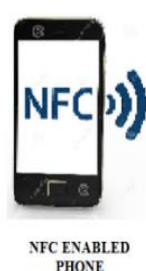

Gambar 1. Teknologi NFC-RFID

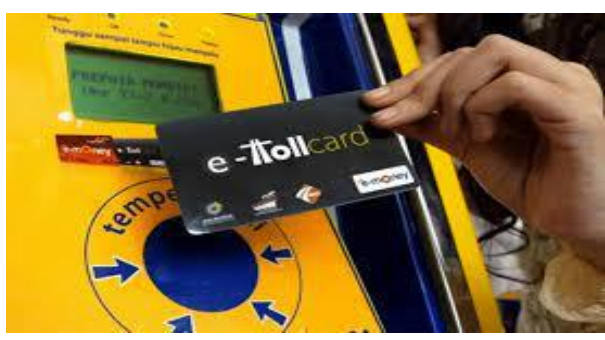

\section{B. VANET-DSRC}

VANET secara garis besar dapat dikelompokkan menjadi kelompok mobile dan kelompok infrastruktur. VANET harus dilengkapi dengan On-Board Unit (OBU) dan Application Unit (AU). OBU bertindak sebagai terminal sekaligus router wireless. Titik akses infrastruktur pada VANET dikenal dengan istilah Road Side Unit (RSU). RSU ditempatkan di lokasi-lokasi strategis di sepanjang jalan, misalkan di persimpangan jalan atau pada lampu lalu lintas. Dalam jaringan vehicular ini, OBU dapat dianggap sebagai node yang bergerak dan RSU adalah node yang diam (statis). RSU dapat tergabung ke Internet melalui Internet Gateway dan OBU dapat terhubung ke Internet melalui RSU atau Hotspot (HS) (Azizah,R.N.,2016).). Hal ini terlihat pada gambar 2.

Pengertian Dedicated short-range communications (DSRC) adalah komunikasi wireless satu arah atau dua arah berjarak pendek sampai menengah (1000 meter) yang di peruntukan untuk otomotif dengan protocol protocol tertentu dan standar. DSRC mempunyai frekuensi operasi di 5,9 GHz (5850-5925 MHz) dengan bandwidth yaitu 75 Mhz, dengan standarisasi teknologi menurut IEEE 802.11a yang menggunakan modulasi Orthogonal frequency-division multiplexing (OFDM).

Dalam komunikasi aktif antara kendaraaan dengan kendaraan (V2V) atau kendaraan dengan infrastruktur (V2I) lebih di pilih menggunakan komunikasi dengan teknologi DSRC di bandingkan dengan WIFI pada frekuensi $2.4 \mathrm{GHz}$. WIFI saat ini sedang dikembangkan dan di aplikasi dalam sistem seluler yang memungkinan banyak penggunaaan yang menyebabkan kekacauan untuk di gunakan dalam komunikasi keselamatan aktif yang sangat tidak bertoleransi terhadap interferensi dan kesalahan sistem. Berikut adalah beberapa alasan penggunaan Sistem DSRC dalam sistem Etol ini di bandingkan dengan WIFI yaitu:

1. Fast Network Acquisition: Aplikasi keamanan aktif memerlukan pembentukan segera komunikasi.

2. Low Latency: aplikasi keamanan aktif harus mengeksekusi dalam jumlah terkecil waktu mungkin.

3. High Reliability: aplikasi keamanan aktif membutuhkan tingkat kehandalan yang tinggi tautan.

4. Priority for Safety Application: aplikasi Keselamatan pada DSRC diberikan prioritas di atas aplikasi non-keamanan.

5. Interoperabilitas: DSRC menjamin interoperabilitas, yang merupakan kunci untuk sukses penyebaran aplikasi keselamatan aktif.

6. Security and Privacy: DSRC menyediakan otentikasi pesan keamanan dan privasi 


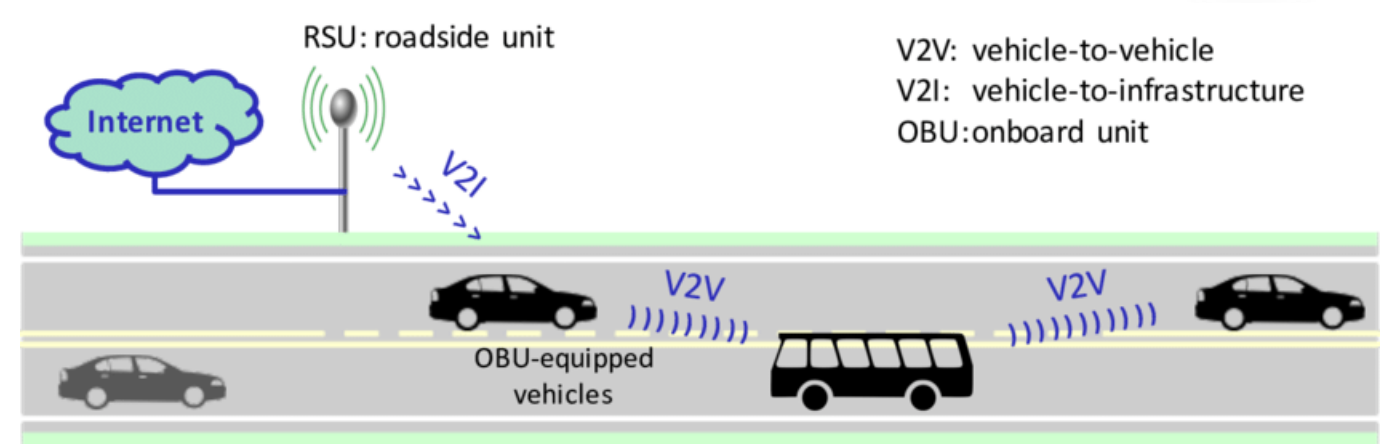

Gambar 2. Teknologi Vanet-DSRC

\section{HASIL \& PEMBAHASAN}

\section{a. NFC-RFID}

\section{- Pengujian Kecepatan Membaca}

Pengujian kecepatan ini untuk menilai kelebihan dan kekurangan dengan sistem yang sebelumnya ada dan sudah berjalan, adapun pengujian kecepatan pembaca sebagai berikut:

Tabel 1. Hasil Pengujian kecepatan Pembaca

\begin{tabular}{ccccc}
\hline NO & PENGUJIAN & Pengujian 1 & Pengujian 2 & Pengujian 3 \\
\hline 1 & Jarak pembaca kartu & $10 \mathrm{~cm}$ & $3 \mathrm{~cm}$ & $5 \mathrm{~cm}$ \\
2 & Kecepatan Pembaca kartu & 5 detik & 2 detik & 3 detik \\
\hline
\end{tabular}

Hasil penelitian ini telah di publikasikan dengan Judul "Pengenalan Surat Tanda Nomor Kendaraan Berbasis Near Field Communication (Nfc) Dengan Aplikasi Android" pada Jurnal Kajian Teknik Elektro volume 2 No. 2 tahun 2017 (Athoillah, A. \& Santoso,K.A. 2017). Dari hasil uji tersenbut bahwa Maksimal waktu tercepat adalah pada jarak $2 \mathrm{~cm}$ yaitu 2 detik. Sehingga penggunaan kartu E-toll dengan sistem NFC ini tidak bias terlalu jauh jarak antara reader dan kartu NFC karena mempengaruhi waktu proses pembacaan pada card reader.

Akan tetapi hasil ini, masih lebih baik dibanding dengan manual sistem yang membutuhkan waktu mencapai 13, 5 detik. Implementasi penggunaan kartu NFC pada gerbang tol dapat mengurangi waktu kemacetan pada gerbang tol dengan sangat signifikan untuk.

\section{b. VANETS-DSRC}

Penggunaan DSRC untuk mendeteksi dan mengumpulkan data yang di gunakan untuk melihat posisi kendaraan serta identifikasi kendaraan sehingga nilai transaksi sesuai dengan jenis kendaraan yang melalui gerbang tol tertentu. Perangkat perangkat. utama dari sistem E-Tol ini adalah terletak pada Transceiver, Camera dan Transponder atau di kenal dengan nama On Board Unit (OBU), hal ini terlihat pada gambar 3 


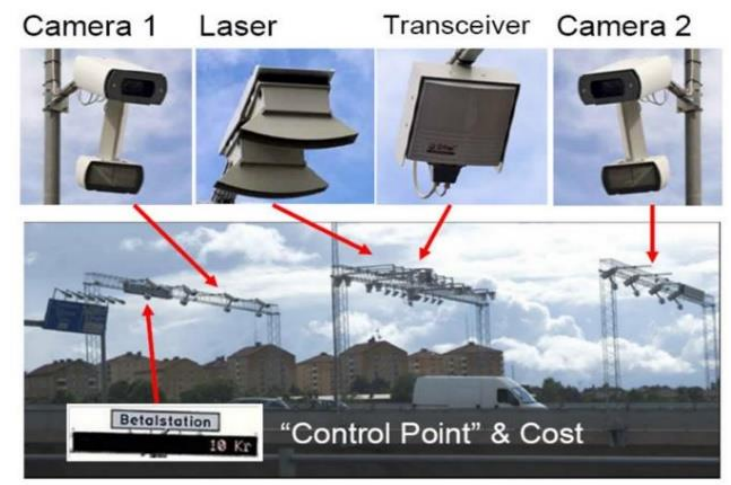

Gambar 3. Transceiver dan camera
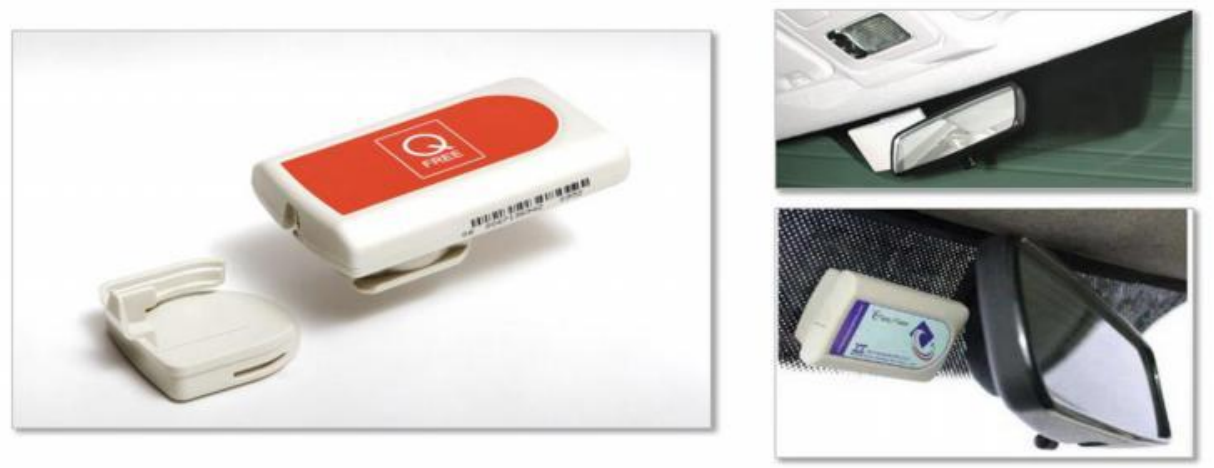

Gambar 3. Transponder atau On Board Unit (OBU)

- Procedure Kerja Sistem Vanet-DSRC

Pada Gambar 4 sistem yang di gunakan adalah OBU terdeteksi oleh transceiver DSRC, lalu data pengguna OBU terdeteksi dan nilai transaksinya jenis kendaraan dan biaya Tol di ruas tol tersebut dan nilai duit yang ada di rekening yang dikhususkan untuk pembiayaan Tol ini terpotong secara otomatis lalu gerbang tol terbuka bagi penggunaan palang tol. Lebih jelasnya terdapat pada Gambar 4 di bawah ini.

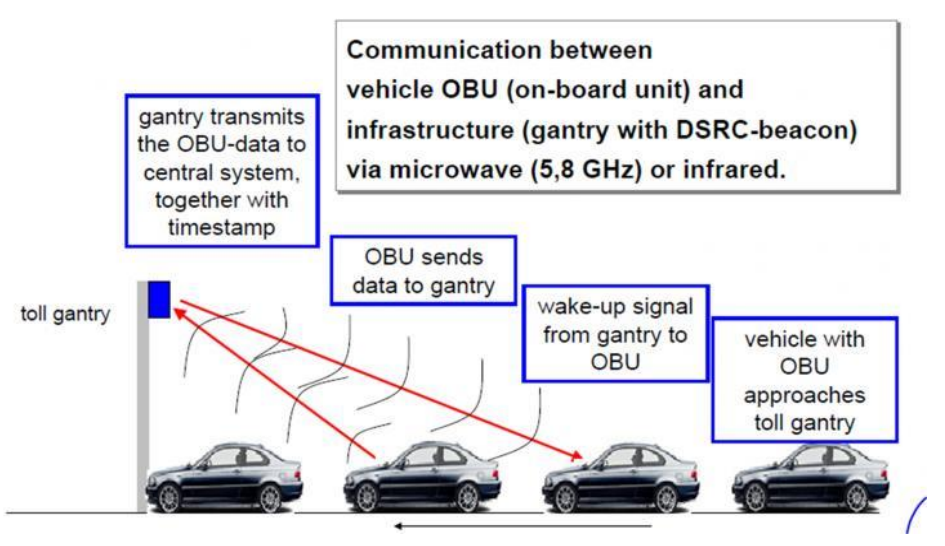




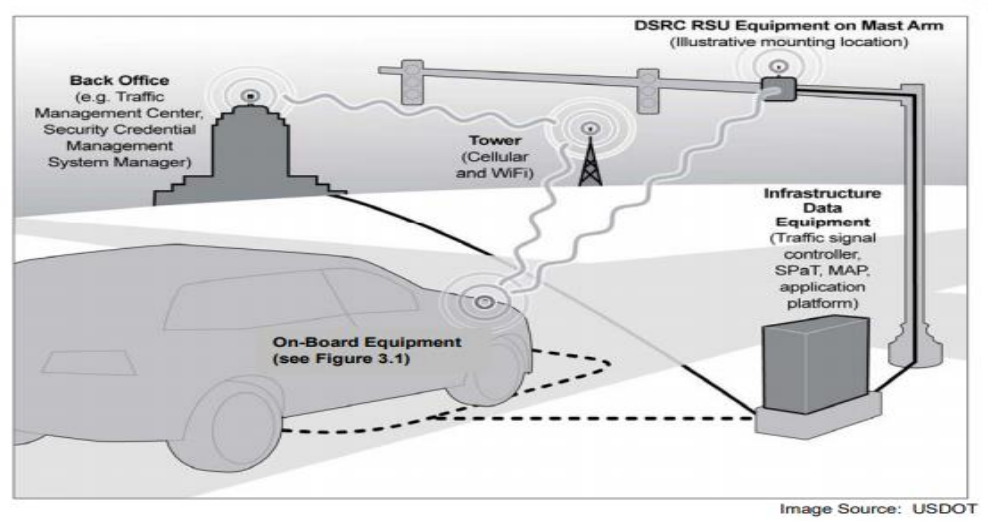

Gambar 4. Sistem Etol dengan VANET-DSRC

Dalam sistem transaksi pembayarannya mengambil sistem transaksi yang bekerjasama dengan Bank sehingga transaksi masuk ke dalam sistem pembayaran dari rekening pengguna.

\section{- Pengujian Kecepatan Membaca}

Dilaporkan pada Pengujian DSRC di Wilayah Amerika serikat bahwa sistem dengan menggunakan DSRC dapat terdeteksi dengan latency kurang dari 100 Millisecond atau secara spesifik berkisar antara 0,0002-0,015 detik dengan jarak kurang dari 1000 meter dengan kecepatan kendaran normal jalan tol. [U.S. Department of Transportation and Applications, 2015].

Pada pengujian gerbang tol Kalimalang II dengan menggunakan sistem DSRC ini kurang dari satu detik dengan kecepatan rata-rata $62 \mathrm{Km} / \mathrm{Jam}$.

\section{SIMPULAN}

Simpulan Berdasarkan hasil pengujian sistem otomatis gerbang tol yang secara pengujian di perlukan untuk dapat mengurangi kemacetan berdasarkan hasil penelitian pada gerbang manual secara rata-rata membutuhkan waktu 13,5 menit per kendaraan dengan sistem otomatis menjadi berkurang dengan rincian sebagai berikut

1. Sistem NFC-RFID secara maksimal membutuhkan waktu berkisar 2-5 detik pada jarak tempel kartu 3-10 cm.

2. Sistem dengan VANETS-DSRC secara maksimal membutuhkan waktu kurang dari 1 detik latency pada kecepatan kendaraan $62 \mathrm{Km} / \mathrm{Jam}$

\section{DAFTAR PUSTAKA}

Winarsih,N., \& Kusumaningrum, J. (2013). Analisis kapasitas gerbang tol karawangan barat. Proceeding Psikologi, Ekonomi, Sastra, Arsitektur \& Teknik Sipil. Vol. 5. 1858-2559.

Jokowi: kerugian akibat macet di jabodetabek capai rp 65 triliun (2019, Jan 8) Liputan6.com. diakses pada Juli 8, 2021, dari https://www.liputan6.com/bisnis/read/3865973/jokowi-kerugian-akibat-macetdi-jabodetabek-capai-rp-65-triliun

Azizah,R.N.(2016).Jaringan ad-hoc vehicular (vanet): tinjauan tentang arsitektur,karakteristik,aplikasi,dan protocol medium access control (mac). Jurnal Pengkajian dan Penerapan Teknik Informatika (PETIR) Vol.9 No.1 28-37

Athoillah, A. \& Santoso,K.A.(2017). Pengenalan surat tanda nomor kendaraan berbasis near field communication (nfc) dengan aplikasi android. Jurnal Kajian Teknik Elektro Vol.2 no.2. 93-104 
Status of the Dedicated Short-Range Communications Technology (2015). U.S. Department of Transportation and Applications. diakses pada Juli 8, 2021 dari www.its.dot.gov

Dahlan Ngebut Saat Bayar Tol, Jantung Bos Telkom Mau Copot (2014). detik.com . diakses pada Juli 8, 2021, dari https://finance.detik.com/berita-ekonomi-bisnis/d2708964/dahlan-ngebut-saat-bayar-tol-jantung-bos-telkom-mau-copot.

Fehr, W. (2014). Overview of dedicated short range communications (dsrc) technology. Research and Innovative Technology Administration (RITA), di akses dari http://www.its.dot.gov/dsrc.

Valentin, C. \& Victor G (2007). Vehicle ad-hoc networks dedicated short-range communication Protocol. "Politehnica" University of Bucharest.

Kresna,R.B. (2011). Desain e-toll dengan near field communication (nfc) technology. E-Indonesia Initiative 2011 (eII2011) Konferensi Teknologi Informasi dan Komunikasi untuk Indonesia14-15 Juni 2011, Bandung

Q-free obu610 dsrc transponder specification,Q-Free. Diakses pada Juli 8 2021, dari https://www.q-free.com 